Citation: Barker, A., dasNair, R., Lincoln, N.B., \& Hunt, N. (2014). Social Identity in people with Multiple Sclerosis: A Meta-synthesis of Qualitative Research. Social Care and Neurodisability, 5(4), 256-267. DOI 10.1108/SCN-05-20140009.

\title{
Social identity in people with multiple sclerosis: a meta-synthesis of qualitative research
}

\author{
Alex B. Barker, Roshan das Nair, Nadina B. Lincoln and Nigel Hunt
}

Alex B. Barker is a Post-

Disclosure: Alex B. Barker, PhD studentship was provided by the MS Society (966/12).

Graduate Research Student,

Dr Roshan das Nair is a

Consultant Clinical

Psychologist \& an Honorary

Associate Professor and

Nadina B. Lincoln is a

Professor of Clinical

Psychology, all are based at

Division of Rehabilitation and

Ageing, University of

Nottingham, Nottingham, UK.

Dr Nigel Hunt is an Associate

Professor, based at Faculty

of Medicine \& Health

Sciences, University of

Nottingham, Nottingham, UK. 


\section{Abstract}

Purpose - Many aspects of the selfare lost as a consequence of having multiple sclerosis (MS). A person's identity can be altered by negative selfconcepts, which are associated with poor psychological wellbeing and can lead individuals to reconstruct their sense of self. The Social Identity Model of Identity Change argues that previously established identities form a basis of continued social support, by providing grounding and connectedness to others to facilitate the establishment of new identities. Family support is a salient factor in adjustment to MS and may enable the establishment of new identities. The purpose of this paper is to investigate identity reconstruction following a diagnosis of MS.

Design/methodology/appro ach - A meta-synthesis of the qualitative literature was conducted to examine the relationship between identity change and family identity of people with MS and other family members. Findings In all, 16 studies were identified that examined identity change and the family following a diagnosis of MS. Coping strategies used by people with MS and their wider family groups, affect the reconstruction of people's identity and the adjustment to MS. Receiving support from the family whilst a new identity is constructed can buffer against the negative effects of identity loss.

Practical implications The family base is strengthened if MS-related problems in daily life are adapted into the individual and family identity using positive coping styles.

Originality/value - This review provides an interpretation and explanation for results of previous qualitative studies in this area.
Keywords Social identity, Family, Qualitative, Multiple sclerosis, Adjustment, Coping Paper type Literature review

\section{Introduction}

Multiple sclerosis (MS) is a neurological condition that affects approximately 100,000 people in the UK (Multiple Sclerosis Society, 2013) and 2.5 million people worldwide (Compston and Coles, 2002). MS is a chronic disease in which the myelin sheaths and axons in the brain and spinal cord are damaged (Compston and Coles, 2008). This leads to a wide range of symptoms, including cognitive and visual impairment, vertigo, fatigue, muscle weakness, ataxia, spasticity, and sexual, bowel and bladder dysfunction (Goldenberg, 2012).

MS can have a devastating impact on a person's sense of self (Boeije et al., 2002). Positive self-concepts are replaced by negative self-concepts. The changes to the person's identity following a diagnosis of MS can have a negative psychological effect on the individual (Haslam et al., 2008), and the individual may experience ongoing psychosocial effects during the two years following diagnosis (Janssens et al., 2003). Psychological difficulties are a common occurrence in people with MS, with high rates of depression (Janssens et al., 2003) and anxiety (Zorzon et al., 2001).

Chronic illnesses, such as MS, can lead to biographical disruption. MS, like other chronic illnesses, "involves a recognition of pain and suffering, possibly even death, which are only seen 
as distant possibilities or the plight of others" (Bury, 1982, p. 169). In this sense chronic illness can be seen as a major disruption to people's lives. The experience of symptoms in everyday life can result in a process of restructuring personal and social resources in an attempt to deal with the uncertain disease progression. Increasing conscious recognition of functional limitations can lead to embarrassment, resulting in social isolation (Bury, 1982). Instead, individuals begin to restrict their social environment to local and familiar territory (Goffman, 1968; Barker and Bury, 1978).

Despite the physical and psychological problems associated with the disease, some people with MS manage to cope well and adapt to living with the illness (Antonak and Livneh, 1995). Two patterns of adapting to identity change have been identified in response to chronic illness (Charmaz, 1995): adapting and bracketing. Adapting, involves acknowledging the impairment and the lost identity and reconstructing a new identity based upon the changed sense of self, whereas bracketing involves compartmentalizing the disease to preserve a sense of the prediagnosis self, in an attempt to recover the lost identity. Whilst the two responses to adapting to identity change appear to be separate responses, Bury (1982), states that in response to biographical disruption, it is only when symptoms become apparent that people attempt to restructure their personal and social resources to respond to the disruption. Due to the relapsing nature of the disease, people with MS may not always be experiencing symptoms, despite being diagnosed. Participants may respond to the biographical disruption of being diagnosed with MS by bracketing the disease and then begin to use adaptive coping styles as symptoms become more apparent.

This difference in adapting to chronic illness has led researchers to investigate the psychological correlates of adjustment to the disease and to investigate individual differences in adapting to MS. In a review of the psychological correlates of adjustment to MS, social support and interaction with others were highly associated with a range of adjustment outcomes, suggesting that social support can facilitate adjustment to MS (Dennison et al., 2009). Characteristics of relationships with others have also been examined, with perceived positive interactions with others being beneficial for adjustment to MS (Dennison et al., 2009). This suggests that the social groups a person belongs to, a person's social identity, could be beneficial for adjustment following diagnosis.

\section{The Social Identity Model of Identity Change (SIMIC)}

The SIMIC (Jetten and Panchana, 2012) supplements an individual-level approach to adjustment and recognizes that social groups (e.g. those centred on family, work, community, sport or religion) provide security, support, purpose and a sense of identity to enable individuals to cope with life transitions. Belonging to a large number of different groups before a lifechanging transition, such as a diagnosis of MS, can protect individuals from the effects of this transition by providing them with groups to fall back on (Haslam et al., 2008). These groups form a secure base for identity reconstruction in that they provide a basis for social support, whilst providing grounding and connectedness to others, allowing people to build new identities. These new identities are integrated and compatible with previous identities, enhancing a person's identity continuity (Jetten and Panchana, 2012), and can reduce the negative effects of identity loss on psychological wellbeing (Haslam et al., 2008). Using social groups to achieve identity reconstruction, forming a new identity which incorporates and acknowledges the disease, appears to be necessary for coming to terms with the disease and reducing the negative psychological impact of MS (Boeije et al., 2002).

\section{Family support}

Family support has been found to be a salient factor in an individual's adjustment to MS (Wineman, 1990). Furthermore; family support is often cited as being the main source of emotional and physical support for people with MS (Irvine et al., 2009), and indeed, those with other neurological conditions (Jones et al., 2011). In a large-scale study of individuals with traumatic brain injury (Jones et al., 2011), a positive correlation between the severity of the injury and life satisfaction could be explained by the person's increased sense of personal identity, which brought them closer to family and other support networks. Individuals are likely to seek 
and receive social support from others who they perceive share their social identity (Haslam et al., 2009). When people are diagnosed with MS, they may attempt to conceal their diagnosis and do not normally perceive themselves as belonging to that social group (Irvine et al., 2009), and because of this, they may seek support from a social group they feel they do belong to, such as the family. Therefore, a diagnosis of MS may increase an individual's family identity, the social support received from this group could provide a secure base for people to acknowledge their emerging identity as a person with MS and incorporate this into their current identity. As symptoms become more prominent, the person with MS may recognize their illness and family members may take on more of a carer role, which could lead people with MS to recognise and incorporate their changing identity in a supportive environment. The SIMIC (Jetten and Panchana, 2012 not wanting to grow old; a SIMIC analysis of driving cessation among older adults.) states that using previous social groups to acknowledge and adjust to identity change has a beneficial effect on psychological wellbeing, because a persons identity continuity is not disrupted by the identity change. Incorporating their emerging identity as a person with MS into their existing pre-diagnosis identity, may lead people to seek and receive support from other people with MS, as predicted by the SIMIC (Jetten and Panchana, 2012).

The psychosocial problems that a person with MS experiences can cause demoralization, which may be accompanied by deterioration in relationships due to the person with MS and those close to them struggling to adapt to the changed person and circumstances (Mohr et al., 1999). The biographical disruption caused by the chronic illness can affect the family group as well as the person with MS (Green et al., 2007). MS affects the family unit as a whole, due to the wide range of symptoms the individual faces (Antonak and Livneh, 1995) and the thought of increased reliance on the family in the future (Irvine et al., 2009; Wineman, 1990). Research on the marital unit has found that it is not only the person with MS who suffers from the psychological effects of the disease, but also their significant others (Janssens et al., 2003; Northouse et al., 1995). Care receivers and their partners' level of distress are highly correlated (Northouse et al., 1995). It is common for family members to become carers for people with MS (Multiple Sclerosis Society, 2007) which can lead to large disruption and change in the family group as members of the family attempt to adapt to the carer identity (Multiple Sclerosis Society, 2007).

An integrative review of qualitative studies, meta-synthesis, was conducted to evaluate identity reconstruction following a diagnosis of MS by drawing together studies to gain an overall impression of the role of identity in adjustment.

\section{Aims}

The aim of this meta-synthesis was to investigate identity reconstruction following a diagnosis of MS, by reviewing qualitative studies of the changes to a person's family identity in people with MS.

\section{Methods}

The meta-ethnographic analytic approach(Noblit and Hare, 1988) was used for this metasynthesis. This approach involves identifying themes across different studies, so that the results of a synthesis are grounded in the data, whilst, allowing a re-conceptualization across studies (Doyle, 2003). The aim was to determine how the studies were related to each other, by identifying common themes, taking into account refutational data, and forming a line of argument to represent the results. A line of argument approach is a form of grounded theorizing, which involves creating a picture of the whole from studies of its parts.

The criteria for inclusion were defined before searching for data. For the purpose of this study, the family was defined as a group of people related by blood, marriage, civil partnership or cohabitation. Studies were considered if they included participants with MS or involved a family member with MS, which explored their experience of living with MS; and discussed their sense of identity. Studies were considered if they used qualitative methods of data collection and analysis. Mixed methods studies were also considered if there was a distinct qualitative component from which data could be extracted. Studies were not excluded on the basis of their 
quality. Any quality issues were considered in the synthesis of the studies to reduce the distortion or the impact of the interpretation of the study.

To ensure a broad and consistent search of the literature across databases a table was created to ensure that all search terms appropriate to the research question were searched in selected databases. (Table I)

The following databases were searched EMBASE (1980-2013 week 42), Medline (1996-October week 3, 2013), PsychINFO (1806-October week 3, 2013), Web of Knowledge (all years), and Science Direct (all years). The search was completed by the first author (ABB) and checked by the second author $(\mathrm{RdN})$.

In all, 218 records were retrieved from the databases (see Figure 1), the relevance of the citations was assessed by the first author and checked by the second author. Duplicates were removed using a reference management programme (endnote), leaving 33 records that were then screened, using their abstracts, to assess suitability for inclusion. In all, 14 records were excluded due to the participants of the study not having MS. Full texts of the remaining 19 were then assessed for inclusion. A further three studies were excluded as they used a mixed methods approach but only provided quantitative results. Solari et al. (2010) used interviews to generate items for a psychometric test, but the results refer to medical communication of MS, not the family relationship. Paliokosta et al. (2009) used interviews to gather demographic information about participants and to assess psychological wellbeing. The interviews did not examine changes in family identity. Lawson et al. (1985) used diaries and interviews to record how people spend their daily lives and analysed these quantitatively.

Totally, 16 studies met the criteria and were included in the meta-synthesis. Each paper was read multiple times before themes and concepts were extracted from the data. Once these themes were identified, they were compared and contrasted across studies. Themes and concepts were grouped together based on their similarities, at which point all of the studies in each group were re-read before forming broad themes based on the understanding of the literature. A line of argument synthesis was then constructed based on how these themes related to each other. The themes, concepts, metaphors and phrases from each study were extracted and organized into a grid. These were then reciprocally grouped together based on the meaning of the theme, concept, metaphor or phrase found in the original text resulting in a list of themes that occurred across studies.

\section{Results and discussion}

The synthesis yielded three overarching themes: "the family as a secure base for identity reconstruction", "the problems encountered with living with MS", and "coping strategies". The most common themes and the studies that endorsed these themes are shown in Table II.

\section{(1) The family as a secure base for identity reconstruction}

This theme was reflected in the primary themes, concepts and phrases of 13 out of the 16 studies. The family unit was often the first to know about the diagnosis (Irvine et al., 2009; Stuart and Sullivan, 1982) and the first to provide social support. In the three studies examining

\section{Table I Summary of search terms}

Research question What are the changes to a person's family identity following a diagnosis of multiple sclerosis?

\begin{tabular}{lllll}
\hline Concept & Multiple sclerosis & Identity & Family & Time since diagnosis \\
Synonyms & MS & Self-social identity & Significant other, next of kin & Duration, onset, advanced \\
Broader & Inflammatory, neurological & Self-concept, identity & Family Group & Psychosocial adjustment \\
Narrower & $\begin{array}{l}\text { Relapsing remitting, } \\
\text { secondary progressive, } \\
\text { primary progressive, benign }\end{array}$ & Self & Husband, wife, partner, & parent, mum, dad, mother, \\
& Chronic conditions & Self-categorisation & & \\
Related terms & father, child, sibling, spouse & \\
Alternative spelling & & & &
\end{tabular}




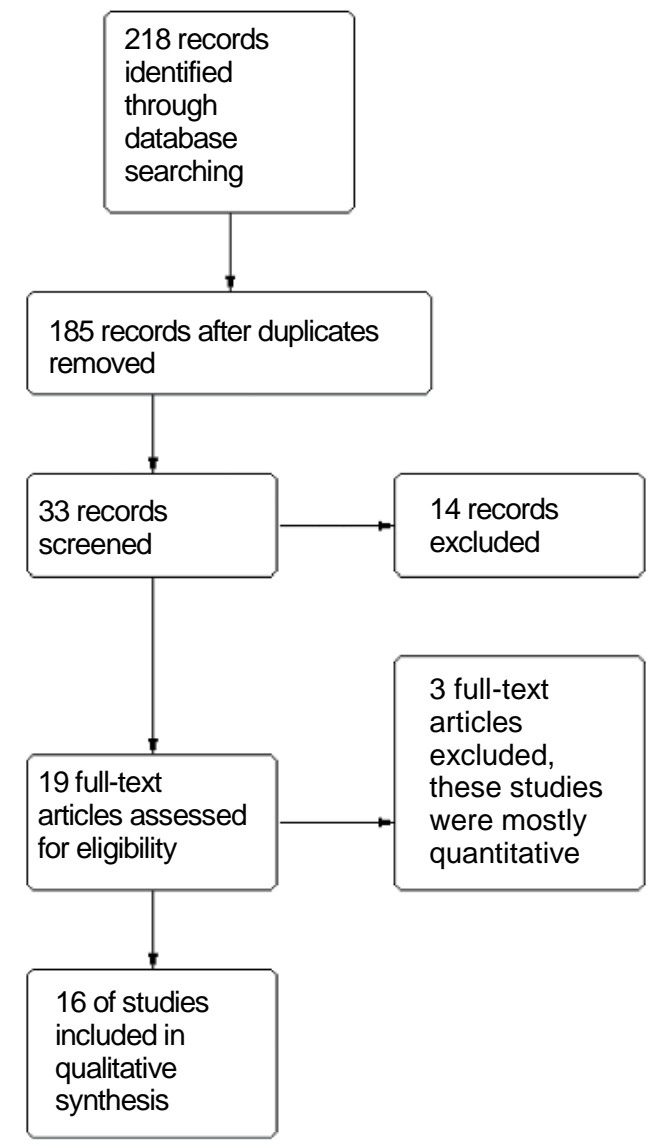

couples, the spouse was described as the main source of support (Boland et al., 2012; Johnson et al., 2010; Douglas et al., 2008). This relationship appeared to be reciprocal (Boland et al., 2012), so that both the person with MS and their partner received support whilst they came to terms with the diagnosis, representing the shared difficulties associated with MS. Mutual support was a common theme identified in three studies (Boland et al., 2012; Johnson et al., 2010; Liedstrom et al., 2010). In studies where the person with MS was single or divorced, other family members, such as parents or children, appeared to be the main source of social support (Boland et al., 2012; Liedstrom et al., 2010).

Using the family as a source of support appeared to be useful for increasing the sense of family identity, this provided grounding for the person with MS. In one study (Boland et al., 2012), sharing domestic duties was seen to be a way in which the family acted as a secure base for identity reconstruction, this was seen as a way of normalizing couples situation and gave them both something to focus on. One study (Douglas et al., 2008) found that the shared experience of coming to terms with the diagnosis strengthened the relationship in a marriage. People with MS recognized that the family was helping them to come to terms with and accept their MS (Liedstrom et al., 2010), the supportive relationships within the family had deepened since diagnosis and this helped with adjusting to the loss of identity caused by the MS. Four studies found that people with MS experienced benefits from their diagnosis (Irvine et al., 2009; Boland et al., 2012; Lexell et al., 2009; Robinson, 1990) for example by: spending more time with the children (Lexell et al., 2009), couples coming closer together and learning to appreciate each other more (Douglas et al., 2008; Liedstrom et al., 2010) and positive changes in perception and outlook (Irvine et al., 2009). 


\begin{tabular}{|c|c|c|c|c|c|c|c|c|c|c|}
\hline Studies/themes & $\begin{array}{c}\text { Shared } \\
\text { domestic } \\
\text { duties }\end{array}$ & $\begin{array}{l}\text { Support } \\
\text { from } \\
\text { oartners } \\
\text { and the } \\
\text { family }\end{array}$ & $\begin{array}{r}\text { Bringing } \\
\text { families } \\
\text { closer } \\
\text { together }\end{array}$ & $\begin{array}{c}\text { Regret } \\
\text { losing } \\
\text { work }\end{array}$ & $\begin{array}{c}\text { Dependency } \\
\text { tension } \\
\text { between the } \\
\text { person with } \\
\text { MS and family } \\
\text { members }\end{array}$ & $\begin{array}{l}\text { Unpredictability } \\
\text { of the disease } \\
\text { and future } \\
\text { plans }\end{array}$ & $\begin{array}{l}\text { Coping } \\
\text { strategies }\end{array}$ & $\begin{array}{l}\text { Accepting } \\
\text { and } \\
\text { adjusting }\end{array}$ & $\begin{array}{l}\text { Benefit } \\
\text { finding }\end{array}$ & $\begin{array}{l}\text { Concealing } \\
\text { symptoms }\end{array}$ \\
\hline Boeije et al. (2002) & & + & + & + & & + & + & + & & \\
\hline Irvine et al. (2009) & & + & & + & + & + & + & + & + & + \\
\hline Boland et al. (2012) & + & + & & & & + & + & + & + & \\
\hline Liedstrom et al. (2010) & & + & + & + & + & + & + & + & & \\
\hline Bowen et al. (2011) & & + & + & & & + & + & + & & \\
\hline Dyck (1995) & + & & & + & + & + & + & & & \\
\hline Lexell et al. (2009) & & & + & & + & & + & + & + & \\
\hline Lexell et al. (2011) & + & + & & & + & & + & & & + \\
\hline $\begin{array}{l}\text { Stuart and Sullivan } \\
\text { (1982) }\end{array}$ & & + & & & & + & & & & \\
\hline $\begin{array}{l}\text { Robinson, (1990) } \\
\text { McLaughlin and }\end{array}$ & & & & & & & + & & + & + \\
\hline Zeeberg (1993) & + & + & & & & & + & & & \\
\hline Johnson et al. (2010) & + & + & & & + & & + & & & + \\
\hline $\begin{array}{l}\text { Boyd and MacMillan } \\
\text { (2005) }\end{array}$ & & + & + & & & & + & & & + \\
\hline Douglas et al. (2008) & & & & & & & + & + & & + \\
\hline Mutch (2010) & & + & + & & + & + & + & + & & \\
\hline Riazi et al. (2012) & & & + & & & + & + & & + & \\
\hline
\end{tabular}

Using the family as a source of support following a diagnosis of MS appears to build a secure base to establish new identities. Seven studies found that the family identity was strengthened following a diagnosis of MS (Douglas et al., 2008; Liedstrom et al., 2010; Lexell et al., 2009; Boeije et al., 2002; Bowen et al., 2011; Boyd and MacMillan, 2005; Riazi et al., 2012), and two studies (Boeije et al., 2002; Irvine et al., 2009) found that after a period of adjustment and receiving support from the family, people with MS were found to enjoy support groups, an activity which some participants with MS admitted they were reluctant to go to after first being diagnosed (Irvine et al., 2009). This shows that using the family as a source of support following a diagnosis of MS allowed participants to incorporate the MS into their identity and seek support from this group.

\section{(2) Problems encountered with living with MS}

The difficulties in coming to terms and living with MS included social withdrawal (Boeije et al., 2002; Irvine et al., 2009) the effects of losing or reducing work (Johnson et al., 2010; Liedstrom et al., 2010; Lexell et al., 2009; Boeije et al., 2002; Irvine et al., 2009; Dyck, 1995), and dependency tensions (Liedstrom et al., 2010; Boeije et al., 2002; Irvine et al., 2009; Dyck, 1995; Lexell et al., 2011). Social support from the family appeared to affect the impact of these problems, as well as the coping strategies used by both the person with MS and the family members (Irvine et al., 2009).

The main source of problems identified in the studies appeared to originate from an inability to accept and adapt to the changed identity of the person with MS, by both the individual and the family. The person with MS struggled to adapt to their new identity and did everything they could to retain their previous identities (Lexell et al., 2011), resulting in a stressful situation when change was unavoidable. Stress was often caused from regret at leaving employment (Liedstrom et al., 2010; Lexell et al., 2009; Boeije et al., 2002; Irvine et al., 2009; Dyck, 1995), but despite this, people with MS often found meaning and enjoyment through engaging with domestic work (Dyck, 1995; Irvine et al., 2009; Lexell et al., 2011). However, this caused further problems, in the form of dependency tension, wherein family members did not know whether they should assist the person with MS or not (Stuart and Sullivan, 1982; Liedstrom et al., 2010; 
Irvine et al., 2009; Dyck, 1995; McLaughlin and Zeeberg, 1993; Douglas et al., 2008) and the person with MS did not always want help due to the enjoyment and meaning they found in being able to do the task. Some participants with MS found that they lacked support and help from family members (Stuart and Sullivan, 1982; Liedstrom et al., 2010), this was sometimes due to shame and feelings of hindrance that the person with MS experienced (Lexell et al., 2009, 2011; Boeije et al., 2002; Irvine et al., 2009; McLaughlin and Zeeberg, 1993). Feelings of shame and hindrance were also associated with wanting to keep the diagnosis private by bracketing it off from the rest of their lives, with participants only telling people when they felt they had to tell (Robinson, 1990; Boeije et al., 2002; Boyd and MacMillan, 2005; Douglas et al., 2008).

People with MS may feel powerless and helpless towards their diagnosis and the progression of the disease (Liedstrom et al., 2010; Boeije et al., 2002; Douglas et al., 2008), this was often associated with tragic illness narratives (Robinson, 1990; Boeije et al., 2002) in which the person with MS bracketed MS from their lives and restricted social contact, especially concerning social support with regard to the illness (Boeije et al., 2002). In four studies (Boland et al., 2012; Boeije et al., 2002; Lexell et al., 2011; Douglas et al., 2008), participants with MS concealed their symptoms to retain a sense of family life, and minimize disruption. People with MS concealed their symptoms because a new symptom resulted in a change to the coping strategies adapted by the family unit (Boland et al., 2012), and the anger that members of the family experienced when a new symptom arose (Douglas et al., 2008). The uncertain progression of MS also caused problems in the family unit by creating a sense of unpredictability, causing the family unit, as a whole, to rethink their plans and future (Boland et al., 2012; Johnson et al., 2010; Douglas et al., 2008; Boeije et al., 2002; Irvine et al., 2009; Dyck, 1995).

Family support appears to influence the extent to which the difficulties in coming to terms and living with MS affect a person. Using the family as a secure base for identity reconstruction can reduce the impact that problems have allowing a person to incorporate the MS into their identity.

\section{(3) Coping}

Participants often used an adapting coping style to cope with problems they encountered, this involved adjusting, accepting and managing problems as they occurred (Boland et al., 2012; Liedstrom et al., 2010; Lexell et al., 2009; Irvine et al., 2009; Boeije et al., 2002; Dyck, 1995; Douglas et al., 2008). Working together to overcome the difficulties encountered in daily life created a sense of "togetherness" in the person with MS with regards to their partner (Boland et al., 2012). This form of coping appears to be positive for psychological wellbeing, as the person with MS is receiving social support from previous groups and identities. However, these groups and identities acknowledge the changed identity of the person with MS, so that they and the support they provide are compatible with the new identity of a person with MS.

In some cases, the family wanted to get more involved in helping the person with MS adjust to their illness, however, the person with MS did not want their support (Johnson et al., 2010; Boeije et al., 2002; Boyd and MacMillan, 2005). The person with MS was attempting to retain a pre-diagnosis identity which was not compatible with the individuals changed sense of self. These participants used a bracketing coping style, which was often associated with negative outcomes, such as social withdrawal (Boeije et al., 2002) and the person with MS being "out of sync" with their spouse (Johnson et al., 2010).

Whilst completing domestic duties to replace paid employment has been identified as a source of tension in other members of the family (Boland et al., 2012), if the family respects the person with MS's need to feel valued and do household chores, this can be seen as a positive way of coping (Boland et al., 2012; Dyck, 1995; Lexell et al., 2011). Establishing a routine to share domestic duties helped to overcome the problem of dependency tension (Boland et al., 2012; Johnson et al., 2010; Dyck, 1995; Lexell et al., 2011; McLaughlin and Zeeberg, 1993).

The varying nature and severity of the symptoms of MS make it an unpredictable disease. The psychological impact of unpredictability alters through diagnosis, remission and relapse (Wilkinson and das Nair, 2013). One way to overcome the unpredictability of MS was to constantly plan daily life (Boland et al., 2012; Johnson et al., 2010; Lexell et al., 2009, 2011). This prevented plans being made for the future, but it prepared the family group to deal more 
effectively with any problems they did encounter (Boland et al., 2012; Johnson et al., 2010; Boeije et al., 2002; Douglas et al., 2008). In other studies this was seen as a hindrance (Stuart and Sullivan, 1982; Boland et al., 2012; Douglas et al., 2008; Dyck, 1995).

Another way of coping with the problems encountered through living with MS was to attempt to preserve a sense of normal family life. This was achieved, for instance, by downplaying pervasive symptoms of the illness (Boland et al., 2012; Douglas et al., 2008; Lexell et al., 2009; Boeije et al., 2002). Whilst this was often related to negative outcomes, such as social withdrawal (Boeije et al., 2002), some studies found that attempting to bracket the illness whilst making small changes to adapt led to positive outcomes, such as bringing the family closer together (Lexell et al., 2009).

Over time, through using the family as a secure base to adjust to their current circumstances, a number of studies found that participants with MS managed to find benefits from their current situation (Boland et al., 2012; Douglas et al., 2008; Lexell et al., 2009; Irvine et al., 2009; Robinson, 1990). This included an acknowledgement that the person with MS felt that they were a better person than they were before diagnosis (Ivvine et al., 2009), having a richer family life (Lexell et al., 2009), and increased strength as a couple (Boland et al., 2012; Douglas et al., 2008).

Due to the progression of MS, new symptoms can appear which lead to new problems emerging in the relationship between the person with MS and their family (Boland et al., 2012). The emergence of a new symptom can lead to a re-evaluation of coping strategies (Johnson et al., 2010). This makes adjusting to MS a constant process.

The use of adaptive coping strategies by both the person with MS and their family can reduce the impact of problems caused by living with MS and reduce the impact of future problems. This aligned coping can bring the family group together, strengthening a person's family identity and allowing a person to incorporate their MS into this identity. However, due to the nature of MS and the presentation of symptoms, people may be at different stages of responding to the biographical disruption and identity change. People may be more inclined to bracket the disease in an attempt to maintain normality, however as symptoms become more prominent, adaptive coping strategies may lead to more positive outcomes. An alignment of coping strategies from both the person with MS and their family group appears to be important.

\section{Line of argument}

The line of argument that appeared out of these themes is that people with MS reported a loss of identity and appeared to use a combination of coping strategies to deal with it. Having a large number of adaptive coping strategies appeared to be associated with positive outcomes such as, family engagement with MS (Boland et al., 2012; Lexell et al., 2011), and increased social activity following an initial withdrawal stage after diagnosis (Irvine et al., 2009). In contrast, having many bracketing coping strategies, compartmentalizing the disease in an attempt to preserve a sense of pre-diagnosis self, was associated with negative outcomes, such as loss of roles, identity and selfworth (Johnson et al., 2010), and social withdrawal (Boeije et al., 2002). The family was recognized as helping the person with MS to come to terms with and accept their MS (Liedstrom et al., 2010). Adjusting to a changed identity appeared to reduce the negative effects of identity loss, as predicted by the SIMIC (Haslam et al., 2008; Jetten and Panchana, 2012). As predicted by the SIMIC (Jetten and Panchana, 2012), the family, a previously established social group, appears to be a useful base for receiving social support and establishing a new identity. Following a period of support and identity reconstruction, people with MS acknowledged that other people with MS shared their identity and they were now willing to receive support from this group. In this way people with MS were reconstructing their identity using the family group as a secure base, as predicted by the SIMIC (Jetten and Panchana, 2012).

Using adaptive coping styles to overcome the problems encountered in everyday life appeared to be positive for the family group. This could be due to the emergence of a shared sense of social identity (Haslam et al., 2009). As predicted by the SIMIC (Jetten and Panchana, 2012), bracketing appeared to have a detrimental effect on psychological wellbeing. The identity that the person was trying to retain was not compatible with their emerging identity as a person 
with MS, however, this could be due to the process of adapting to the chronic illness and the biographical disruption this can cause.

The family can provide a secure base for identity reconstruction by providing support and helping people with MS adjust to their emerging identity as a person with MS. This secure base was further strengthened if problems encountered through everyday life with MS were adapted into the individual and family identity using positive coping styles. Support from the family group, an in-group, may enable the person with MS to accept their new personal identity and seek support from other people with MS, a previous out-group (Jetten and Panchana, 2012). This separation of the self-from their peers has been reported in the literature (Irvine et al., 2009) and appears to be due to the reluctance to be associated with a stigmatized group.

\section{Limitations}

The review was limited by the paucity of research investigating the role of the family on identity reconstruction in people with MS. The participants were all from Europe or North America; therefore, caution should be applied when generalizing to other settings. The meta-synthesis examined studies that were methodologically different, and without knowledge of the epistemological stances of the studies, it is likely that some content from the primary studies may have been lost.

A constructivist approach was used, in that all studies, despite their flaws, were considered to contribute to the area of investigation. No quality appraisal was used, some authors consider it inappropriate for qualitative reviews to use appraisal tools due to discrepancies in how these tools appraise the quality of studies and the many different research designs, and theoretical approaches used in qualitative research (Sherwood, 1997; Dixon-Woods et al., 2004).

The lack of a grey literature search and the decision to exclude studies of mixed-aetiology samples, may have affected the results. It would have been be difficult to tease out MSspecific information from mixed-aetiology studies, and including such non-specific data would increase the heterogeneity of the findings. Only studies published in peer reviewed journals were included, because these could be systematically searched.

\section{Conclusions and implications}

This meta-synthesis suggests that there are benefits from using the family to establish a new identity after the changes to identity that can occur due to a diagnosis of MS. "Adapting" or "bracketing" can be used as ways of coping with the difficulties arising out of living with MS. Adapting to the daily challenges and problems faced with living with MS appeared to be associated with positive outcomes, allowing the family to remain a secure base to establish a new identity. Bracketing appeared to be a way of attempting to preserve a pre-diagnosis identity, rather than establishing a new identity, which may have a detrimental effect on psychological wellbeing (Haslam et al., 2008; Jetten and Panchana, 2012). However, the two forms of coping could be due to different stages of adapting to the chronic illness.

The family was not always successful in providing a secure base for identity reconstruction. In these cases support groups might be beneficial. Some people with MS were able to establish new identities after a period of adjustment (Boeije et al., 2002; Irvine et al., 2009), and normalizing a diagnosis of MS by attending support groups may allow a person rebuild their social identity. This has its benefits: the shared social identity of members of stigmatised groups provides a basis for shared social support that can provide individuals with the emotional, intellectual, and material resources to cope with and resist the injustice of discrimination, prejudice and stigma (Levine et al., 2002).

The study indicates the role of the family in forming a new identity following a diagnosis of MS. By providing information on effective coping styles in response to living with MS, to both the person with MS and their family members, new identities may be formed which reduce the negative effects of the loss of identity. Whilst previous research has shown that the family can be a salient factor in coming to terms with a diagnosis of MS, this meta-synthesis provides a link 
to the SIMIC to explain how and why this relationship could help in this situation and shows some support that these relationships can enable a person to establish new identities:

' the family can provide a secure base for identity reconstruction;

' a number of problems are faced when coming to terms with the diagnosis of MS; and

' coping styles may reflect stages of adaptation to MS, however, adaptive coping was linked to more positive outcomes.

\section{References}

Antonak, R.F. and Livneh, H. (1995), "Psychosocial adaptation to disability and its investigation among persons with multiple sclerosis", Social Science \& Medicine, Vol. 40 No. 8, pp. 1099-108.

Barker, J. and Bury, M.R. (1978), "Mobility and the elderly: a community challenge", in Carver, V. and Liddiard, P. (Eds), An Ageing Population, Hodder and Stoughton,Sevenoaks, pp. 179-90.

Boeije, H.R., Duijnstee, M.S., Grypdonck, M.H. and Pool, A. (2002), "Encountering the downward phase: biographical work in people with multiple sclerosis living at home", Social Science \& Medicine, Vol. 55 No. 6, pp. 881-93.

Boland, P., Levack, W.M.M., Hudson, S. and Bell, E.M. (2012), "Coping with multiple sclerosis as a couple: "peaks and troughs" - an interpretative phenomenological exploration", Disability and Rehabilitation, Vol. 34 No. 16, pp. 1367-75.

Bowen, C., Maclehose, A. and Beaumont, J.G. (2011), "Advanced multiple sclerosis and the psychosocial impact on families", Psychology \& Health, Vol. 26 No. 1, pp. 113-27.

Boyd, J.R. and Macmillan, L.J. (2005), "Experiences of children and adolescents living with multiple sclerosis", The Journal of Neuroscience Nursing: Journal of the American Association of Neuroscience Nurses, Vol. 37 No. 6, pp. 334-42.

Bury, M. (1982), "Chronic illness as biographical disruption", Sociology of Health \& IIIness, Vol. 4 No. 2, pp. 167-82.

Charmaz, K. (1995), "The body, identity, and self: adapting to impairment", Sociological Quarterly, Vol. 36 No. 4, pp. 657-80.

Compston, A. and Coles, A. (2002), "Multiple sclerosis", Lancet, Vol. 360 No. 9333, p. 648.

Compston, A. and Coles, A. (2008), "Multiple sclerosis", Lancet, Vol. 372 No. 9648, pp. 1502-17.

Dennison, L., Moss-Morris, R. and Chalder, T. (2009), "A review of psychological correlates of adjustment in patients with multiple sclerosis", Clinical Psychology Review, Vol. 29 No. 2, pp. 141-53.

Dixon-Woods, M., Shaw, R.L., Agarwal, S. and Smith, J.A. (2004), "The problem of appraising qualitative research", Qual Saf Health Care, Vol. 13 No. 3, pp. 223-5.

Douglas, C., Windsor, C. and Wollin, J. (2008), "Understanding chronic pain complicating disability: finding meaning through focus group methodology", Journal of Neuroscience Nursing, Vol. 40 No. 3, pp. 158-68.

Doyle, L.H. (2003), "Synthesis through meta-ethnography: paradoxes, enhancements, and possibilities", Qualitative Research, Vol. 3 No. 3, pp. 321-44.

Dyck, I. (1995), "Hidden geographies - the changing lifeworlds of women with multiple-sclerosis", Social Science \& Medicine, Vol. 40 No. 3, pp. 307-20.

Goffman, E. (1968), Stigma: Notes on the Management of Spoiled Identity Harmondsworth, Penguin, New York, NY.

Goldenberg, M.M. (2012), "Multiple sclerosis review”, Pharmacy\& Therapeutics, Vol. 37 No. 3, pp. 175-84.

Green, G., Todd, J. and Pevalin, D. (2007), "Biographical disruption associated with multiple sclerosis: using propensity scoring to assess the impact”, Soc. Sci. Med., Vol. 65 No. 3, pp. 524-35.

Haslam, C., Holme, A., Haslam, S.A., lyer, A., Jetten, J. and Williams, W.H. (2008), "Maintaining group memberships: social identity continuity predicts well-being after stroke", Neuropsychological Rehabilitation, Vol. 18 Nos 5/6, pp. 671-91. 
Haslam, S.A., Jetten, J., Postmes, T. and Haslam, C. (2009), "Social identity, health and well-being: an emerging agenda for applied psychology”, Applied Psychology-an International Review-Psychologie Appliquee-Revue Internationale, Vol. 58 No. 1, pp. 1-23.

Irvine, H., Davidson, C., Hoy, K. and Lowe-Strong, A. (2009), "Psychosocial adjustment to multiple sclerosis: exploration of identity redefinition", Disability and Rehabilitation, Vol. 31 No. 8, pp. 599-606.

Janssens, A.C., Van Doorn, P.A., De Boer, J.B., Van Der Meche, F.G., Passchier, J. and Hintzen, R.Q. (2003), "Impact of recently diagnosed multiple sclerosis on quality of life, anxiety, depression and distress of patients and partners", Acta Neurol Scand, Vol. 108 No. 6, pp. 389-95.

Jetten, J. and Panchana, N. (2012), "Not wanting to grow old; a social identity model of identity change (SIMIC) analysis of driving cessation among older adults", in Jetten, J., Haslam, A.S. and Haslam, C. (Eds), The Social Cure: Identity, Health and Well-Being, Psychology Press, Hove \& New York, NY, pp. 97-115.

Johnson, K., Starks, H., Morris, M., Yorkston, K. and Gray, R. (2010), "Being in- or out-of-sync: a qualitative study of couples' adaptation to change in multiple sclerosis", Disability and Health Journal, Vol. 32 No. 2, pp. 196-206.

Jones, J.M., Haslam , A., Jetten, J., Williams, W.H., Morris, R. and Saroyan, S. (2011), "That which doesn't kill us can make us stronger (and more satisfied with life): the contribution of personal and social changes to well-being after acquired brain injury", Psychology and Health, Vol. 26 No. 1, pp. 353-69.

Lawson, A., Robinson, I. and Bakes, C. (1985), "Problems in evaluating the consequences of disabling illness: the case of multiple sclerosis”, Psychological Medicine, Vol. 15 No. 3, pp. 555-79.

Levine, M., Cassidy, C., Brazier, G. and Reicher, S. (2002), "Self-categorisation and bystander nonintervention: two experimental studies", Journal of Applied Social Psychology, Vol. 7 No. 7, pp. 1452-63.

Lexell, E.M., Iwarsson, S. and Lund, M.L. (2011), "Occupational adaptation in people with multiple sclerosis", OTJR-Occupation Participation and Health, Vol. 31 No. 3, pp. 127-34.

Lexell, E.M., Lund, M.L. and Warsson, S. (2009), "Constantly changing lives: experiences of people with multiple sclerosis", American Journal of Occupational Therapy, Vol. 63 No. 6, pp. 772-81.

Liedstrom, E., Isaksson, A.K. and Ahlstrom, G. (2010), "Quality of life in spite of an unpredictable future: the next of kin of patients with multiple sclerosis", Journal of Neuroscience Nursing, Vol. 42 No. 6, pp. 331-41.

Mclaughlin, J. and Zeeberg, I. (1993), "Self-care and multiple sclerosis: a view from two cultures", Social Science \& Medicine, Vol. 37 No. 3, pp. 315-29.

Mohr, D.C., Dick, L.P., Russo, D., Likosky, W., Pinn, J., Boudewyn, A.C. and Goodkin, D.E. (1999), "The psychosocial impact of multiple sclerosis: exploring the patient's perspective", Health Psychology, Vol. 18 No. 4, pp. 376-82.

Multiple Sclerosis Society (2007), "Caring for someone with MS", Multiple Sclerosis Society, London, available at: http://www.mssociety.org.uk/ms-resources/caring-someone-ms-booklet (accessed 17 October 2014).

Multiple Sclerosis Society (2013), "What is MS?", available at: www.mssociety.org.uk. (accessed 13 March 2013).

Mutch, K. (2010), "In sickness and in health: experience of caring for a spouse with MS" British Journal of Nursing, Vol. 19 No. 4, pp. 214-19.

Noblit, G.W. and Hare, R.D. (1988), Meta-Ethnography: Synthesizing Qualitative Studies, Sage Publications, Newbury, Park, CA.

Northouse, L.L., Dorris, G. and Charron-Moore, C. (1995), "Factors affecting couples' adjustment to recurrent breast cancer”, Social Science and Medicine, Vol. 41 No. 1, pp. 69-76.

Paliokosta, E., Diareme, S., Kolaitis, G., Tsalamanios, E., Ferentinos, S., Anasontzi, S., Lympinaki, E., Tsiantis, A., Tsiantis, J., Karageorgiou, C. and Romer, G. (2009), "Breaking bad news: communication around parental multiple sclerosis with children”, Families Systems \& Health, Vol. 27 No. 1, pp. 64-76.

Riazi, A., Bradshaw, S.A. and Playford, E.D. (2012), "Quality of life in the care home: a qualitative study of the perspectives of residents with multiple sclerosis", Diability Rehabilitation, Vol. 34 No. 24, pp. 2095-102.

Robinson, I. (1990), "Personal narratives, social careers and medical courses: analysing life trajectories in autobiographies of people with multiple sclerosis", Social Science \& Medicine, Vol. 30 No. 11, pp. 1173-86.

Sherwood, G. (1997), "Meta-synthesis: merging qualitative studies to develop nursing knowledge", Int J Human Caring, Vol. 3 No. 1, pp. 37-42. 
Solari, A., Mattarozzi, K., Vignatelli, L., Giordano, A., Russo, P.M., Uccelli, M.M., D’alessandro, R., Grp, S.I.T. and Grp, G. (2010), "Development and validation of a patient self-assessed questionnaire on satisfaction with communication of the multiple sclerosis diagnosis", Multiple Sclerosis, Vol. 16 No. 10, pp. 1237-47.

Stuart, D.C. and Sullivan, T.J. (1982), "Illness behaviour and the sick role in chronic illness - the case of multiple sclerosis", Social Science \& Medicine, Vol. 16 No. 15, pp. 1397-404.

Wilkinson, H.R. and Das Nair, R. (2013), "The psychological impact of the unpredictability of multiple sclerosis: a qualitative literature meta-synthesis”, British Journal of Neuroscience Nursing, Vol. 9 No. 4, pp. 172-8.

Wineman, N.M. (1990), "Adaptation to multiple-sclerosis - the role of social support, functional disability, and perceived uncertainty", Nursing Research, Vol. 39 No. 5, pp. 294-9.

Zorzon, M., Demasi, R., Nasuelli, D., Ukmar, M., Mucelli, R.P., Cazzato, G., Bratina, A. and Zivadinov, R. (2001), "Depression and anxiety in multiple sclerosis. A clinical and MRI study in 95 subjects", J. Neurol., Vol. 248 No. 5, pp. 416-21.

\section{Corresponding author}

Alex B. Barker can be contacted at: Iwxabb@nottingham.ac.uk 